\title{
É HORA DA RODA, VAMOS OUVIR UMA HISTÓRIA? A contação de histórias como possibilidade de humanizar tempos e espaços na educação infantil
}

\author{
Fernanda Gonçalves ${ }^{1}$ (UFSC) \\ Gisele Gonçalves $^{2}$ (UFSC)
}

\section{Resumo}

O presente texto tem como objetivo tecer uma reflexão a respeito da relação das crianças com as contações de histórias, a partir de uma experiência vivenciada no Estágio Supervisionado em Educação Infantil no Curso de Pedagogia da Universidade Federal de Santa Catarina. O grupo onde aconteceu o estágio era composto por 26 crianças, com idade entre cinco e seis anos, em uma creche conveniada à Rede Municipal de Florianópolis. Nosso foco se constituiu nos momentos da roda, principalmente de contações de histórias, bem como a formação dos pequenos leitores literários. Primeiramente versaremos sobre as concepções de criança, infância, tempos e espaços que orientaram nosso olhar e nossa prática durante as vivências do estágio. Por fim, desdobraremos nossas análises sobre os momentos de contações de histórias que aconteceram na roda. Um lugar de ouvir grandes histórias, do lúdico e de encantamento, que construímos junto às crianças.

Palavras-chave: Criança. Infância. Roda. Contação de histórias. Tempos e Espaços.

Neste artigo apresentaremos nossas vivências realizadas durante a disciplina de Estágio Supervisionadas em Educação Infantil ${ }^{3}$, que

\footnotetext{
${ }^{1}$ Mestranda em Educação no Programa de Pós-Graduação em Educação (PPGE) na Universidade Federal de Santa Catarina, Linha Educação e Infância.

${ }^{2}$ Mestranda em Educação no Programa de Pós-Graduação em Educação (PPGE) na Universidade Federal de Santa Catarina, Linha Educação e Infância.

${ }^{3}$ Este texto é resultado do relatório final do Estágio Supervisionado em Educação Infantil para a conclusão do curso de Pedagogia pela Universidade Federal de Santa Catarina (Florianópolis - SC), no primeiro semestre de 2012. O Estágio Supervisionado em Educação Infantil do Curso de Pedagogia da UFSC aconteceu em dois momentos: Estágio Supervisionado em Educação Infantil I e II, que somam dois semestres para a realização das vivências no campo de estágio. Nestes dois
} 
aconteceu na Creche São Francisco de Assis, conveniada à Rede Municipal de Florianópolis. Experienciamos, nesta circunstância, o lugar de professoras de educação infantil, estabelecendo um diálogo entre teoria e prática, reflexão tão cara para nossa formação como Pedagogas. O estágio aconteceu no Grupo de Trabalho V (GTV - termo utilizado para a identificação do Grupo na Instituição), com 26 crianças, meninos e meninas de cinco a seis anos de idade.

Tomamos como objeto de análise o momento da roda e as contações de histórias que aconteceram nesse lugar - socialmente construído com as crianças, leitores-ouvintes literários (Debus, 2009) em formação. Compreendendo o espaço da creche como um lugar privilegiado de viver a infância e, como um espaço acolhedor de emancipação das crianças.

Como pressuposto, embasamo-nos em uma concepção de educação infantil que pondera as condições históricas e sociais que marcam o cotidiano das instituições de educação infantil e que levam em conta suas especificidades, mas principalmente, que tome a criança como foco para a ação educativa. Enfatiza-se uma concepção de criança "como sujeito social de direitos, um ser completo em si mesmo, que pensa, se expressa por meio de múltiplas linguagens, que produz cultura e é produzido numa cultura" (Rocha e Ostetto, 2008, p.104). Neste sentido, a principal preocupação "é a própria criança: seus processos de

semestres realizamos ainda, observações participantes, com objetivo de conhecer as crianças, exercitando um olhar sensível mediante suas vivências e, nos aproximando do Grupo de forma respeitosa. Realizamos também, os registros das observações, discussão e orientação de tais registros sob a orientação da Professora Orientadora. Por fim, desenvolvemos o planejamento das proposições como resultado de todo processo de observação e análise dos registros. Usamos o termo proposições para falar sobre os momentos em que propomos intencionalmente vivências para o Grupo, a partir do planejamento previamente realizado. 
constituição como seres humanos em diferentes contextos sociais, suas culturas, suas capacidades intelectuais, criativas, estéticas, expressivas e emocionais" (Batista et al, 2004, p. 02).

Há um esforço de se delinear a especificidade do trabalho juntamente às crianças de 0 a 6 anos de idade no interior das instituições de educação infantil, "cujas práticas sociais são distintas das práticas domésticas, escolares e hospitalares" (Batista et al, 2004, p. 02). Com base nestes pressupostos, o estágio vivenciado na $8^{\mathrm{a}}$ fase do curso de Pedagogia, na Universidade Federal de Santa Catarina, mostra-se como uma possibilidade de pensar a teoria e a prática de maneira indissociável, refletindo assim "a organização do cotidiano das crianças e o viver da infância nas instituições de educação infantill" (Batista et al, 2004, p.04).

Com o presente texto temos como objetivo refletir e ponderar sobre a relação das crianças do GTV com as proposições realizadas durante as vivências do estágio, especificamente as contações de histórias. Portanto, nosso foco de analise é o momento da roda de contações de histórias como possibilidade de significar tempos e espaços no cotidiano da educação infantil e a formação dos pequenos leitores literários.

\section{O tempo e o espaço da creche: um lugar socialmente construído}

O espaço se projeta ou se imagina; o lugar se constrói. Constrói-se a partir do fluir da vida, das relações que ali são travadas e a partir do espaço como suporte; o espaço, portanto, está sempre disponível e disposto para converter-se em lugar, para ser construído. (Agostinho, 2004, p. 02). 
As crianças passam horas dos seus dias nos espaços das instituições de educação infantil. Muitas delas frequentam as instituições desde muito pequenas e ali vão se constituindo como seres humanos, apropriando-se da cultura historicamente construída.

Ao ponderar sobre o número de horas que as crianças passam dentro das instituições de educação infantil, torna-se ainda mais preocupante $\mathrm{o}$ fato de estes espaços não serem convidativos, confortáveis, agradáveis, enfim, um lugar tomado de significado e de sentido para os pequenos.

Os espaços da instituição de educação infantil devem ser intencionalmente qualificados, pensados e planejados para que as crianças se sintam convidadas e acolhidas a agir sobre ele. Para tanto, as professoras tem a responsabilidade fundamental de pensar este espaço, disponibilizando novos elementos, observando as vivências infantis, para daí ponderar sobre as possibilidades de reorganização dos ambientes, principalmente, respeitando as crianças como participantes ativas deste processo.

O espaço historiciza o que é vivido e os atores sociais devem sentir "que toda instituição, incluindo espaço, materiais e projetos, valoriza e mantém sua interação e comunicação." (Rinaldi Apud Gandini, 1999, p. 47). Para nós, o Estágio Supervisionado em Educação Infantil se apresenta como possibilidades múltiplas. Sobretudo como possibilidade de entender a complexa rotina do cotidiano das instituições de educação infantil, a organização do tempo e do espaço e as relações que ali se estabelecem, com o intuito de estruturar uma 
estratégia de ação pedagógica considerando um contínuo processo de investigação do universo infantil.

Por meio do olhar sensível e atento que conseguimos observar os fatos que acontecem no cotidiano e perceber o grupo, bem como cada criança que dele faz parte. Perceber suas dúvidas e angústias, seus medos e anseios, suas subjetividades e suas particularidades. É o momento de se encontrar com o grupo, estreitar as relações que são estabelecidas e de perceber este coletivo. Esta ideia de observar a criança e depois registrar o observado "não está relacionada apenas aos seus processos de desenvolvimento, mas também aos seus conhecimentos, às suas produções, manifestações, preferências, etc." (Rocha e Ostetto, 2008, p. 109).

Logo, para uma prática pedagógica intencional e qualificada para as crianças pequenas temos que ter ciência das especificidades da educação infantil e das ações que qualificam essa prática, como observações, registros, planejamentos e avaliações. Dizemos de forma plural, pois são instrumentos que auxiliam, organizam e orientam a prática e ação do professor de educação infantil e devem ser realizadas constantemente, diariamente e concomitantemente. Há uma relação intrínseca entre todas estas práticas que sustentam o trabalho pedagógico, por isso a simultaneidade das ações. Pois, trata-se de um ciclo pedagógico de ações que se entrelaçam na "aventura" do cotidiano da educação infantil.

A partir do exercício do olhar sensível, durante as tardes de observações, percebemos que os momentos da roda não pareciam confortáveis, como também, o forte interesse das crianças pelas contações de histórias e livros de literatura infantil. Foi assim que 
nasceu nosso projeto de proposição: a partir do interesse das crianças e do que compreendemos como direito dos pequenos - como, por exemplo, o espaço da roda como um lugar (Agostinho, 2004) repleto de sentidos e significados, confortável e agradável de estar.

\section{O espaço da roda como um lugar de novas experiências: do lúdico e de encantamentos por meio da narrativa infantil}

Ao cirandar pelas linhas e entrelinhas de livros tão cheios de colorido e vida, tão próximos das coisas prazerosas e gestos ternurizantes, por certo a criança pequena tecerá leituras e se constituirá leitor (Debus, 2006, p.43).

A partir de nossas observações, percebemos o grande interesse das crianças pela Literatura Infantil, pelos livros e pela contação de histórias: eram pequenos leitores em formação adquirindo gosto pela literatura. Não era qualquer história que os envolvia, mas uma boa narrativa causava verdadeiro encantamento.

Percebemos também que em alguns momentos da roda as crianças se distraíam facilmente, dispersavam-se e, os diferentes elementos que eram trazidos para ser compartilhado, nem sempre chamavam a atenção dos pequenos. Com um olhar sensível, observamos que as crianças podiam estar se sentindo "desconfortáveis" naquele espaço. A roda parecia pouco "convidativa" da forma que acontecia, as crianças sentavam no chão sem tapetes ou almofadas. Não havia aconchego neste momento, as crianças pareciam não querer "estar em roda". 
Portanto, com o intuito de repensar o tempo e o espaço, procuramos, durante o período de planejamento, pensar possibilidades de reorganizar o espaço da roda, no sentido de tentar humanizá-lo, tornando-o um verdadeiro lugar das crianças:

No cotidiano da Educação Infantil, a roda de conversa vem sendo entendida e assumida como uma atividade significativa, na qual a criança, constituindo-se como sujeito da fala (e da escuta), é desafiada a assumir um papel mais ativo na comunicação. Configura-se como um espaço em que as crianças possam dialogar em situações significativas e variadas, partilhar e confrontar ideias, onde a liberdade da fala e da expressão proporcionam ao grupo como um todo, e a cada indivíduo em particular [...]. (De Angelo, 2011, p.60)

Tornar o espaço da roda um lugar para as crianças significa entender este espaço como imprescindível e privilegiado de diálogo, respeitoso e de tomada de decisões importantes do grupo. Ou seja, significa a possibilidade de maior aproximação, um momento de estreitamento de vínculos, de descobertas, do novo, de ouvir histórias, de contar novidades, enfim, um espaço que entendemos ser fundamental e que deve ser privilegiado no contexto de educação infantil.

Logo, durante o período de proposições ${ }^{4}$ com as crianças procuramos proporcionar diferentes momentos de roda: de contação de histórias, de escrita de cartas, de novidades, de escolha de nome para o grupo e de contato com os livros de literatura infantil, os quais foram

4 O período de proposições é o tempo em que colocamos nosso projeto de proposição "em prática". Ou seja, realizamos as vivências previamente planejadas e ensaiamos nosso lugar de professoras. Este, aconteceu durante duas semanas, somando 6 dias (3 dias em cada semana). 
intencionalmente escolhidos por nós visando à formação dos pequenos leitores-ouvintes literários (Debus, 2006).

Para tanto, utilizamos a coleção de livros da Bruxa Onilda e dentre as obras podemos destacar: As memórias da Bruxa Onilda (1998), O Casamento da Bruxa Onilda (2003), Bruxa Onilda e a Macaca (2004) e Bruxa Onilda vai a Paris (2003). Esta escolha foi feita, pois, o Grupo já vinha trabalhando sobre os contos bruxólicos da Ilha de Florianópolis (SC) pelas professoras regentes. As histórias da Bruxa Onilda se mostraram assim, como possibilidade interessante de dialogar com o projeto. Sobre a protagonista das narrativas:

A Bruxa Onilda é a personagem principal de uma série de narrativas escritas por Enric Larreula e ilustradas por Roser Capdevila, autores catalães, que, em suas histórias, narram as aventuras dessa personagem que, apesar de estar munida de poderes mágicos, enfrenta, constantemente, alguma dificuldade. Seus problemas ou situações difíceis são, muitas vezes, oriundos justamente do uso incorreto de sua magia, ou então, das atrapalhações que a personagem, por inocência, acaba realizando. (Laitano, 2008, p.02)

Entendemos que é por meio das narrativas que as crianças mergulham no mundo da palavra escrita de maneira contextualizada. Uma vez que o interesse pela escrita nos chamou muito a atenção. Com o intuito de contemplar - ainda que minimamente - o interesse das crianças, focalizamos nossas proposições no espaço da roda como um lugar de novas experiências, do lúdico e de possíveis encantamentos por meio da narrativa infantil: tornamos o espaço um lugar de ouvir grandes histórias e conhecer cada vez mais a palavra, tanto oral quanto escrita. 
Concordante com Eliane Debus (2006), compreendemos que a contação de histórias pode contribuir na aprendizagem da leitura escrita. São pelas narrativas que as crianças conhecem novos vocabulários e entram em contato "com estratégias de linguagem, já que a estrutura início, meio e fim das narrativas auxilia a criança na elaboração de suas próprias histórias. O leitor-ouvinte começa a ser exposto naturalmente ao mundo ficcional, o que lhe desperta a sensibilidade e a criatividade" (p.75).

A roda mostrou-se para nós como um espaço de interações entre todos, como um lugar prazeroso de ouvir e ler histórias. Portanto, procuramos significar os momentos de roda, proporcionando elementos para torná-la mais convidativa e confortável às crianças.

Pautadas em nosso planejamento, o qual foi cautelosamente e intencionalmente pensado a partir das nossas observações com o Grupo - intrínseco a todo o aporte teórico que viemos discutindo durante o curso de Pedagogia, mais especificamente na Habilitação em Educação Infantil - iniciamos nossas proposições com as crianças.

$\mathrm{Na}$ primeira roda explicamos o sentido do estágio para as crianças, procurando apresentá-lo de forma concreta, ilustrando a nossa intencionalidade a partir do título que demos ao projeto de proposições: A Hora da Roda: vamos ouvir uma história? Nesse momento as crianças também expuseram alguns questionamentos e contaram novidades. No entanto, não existia um espaço confortável para que acontecesse a roda. Não havia tapetes, não havia almofadas; ela acontecia no chão duro e gelado. Por isto, resolvemos reorganizar a sala como um "mini-teatro" com as próprias cadeiras. Por fim, contamos a primeira história: As memórias da Bruxa Onilda (1998). 
As crianças ficaram muito curiosas com a narrativa, pois, o marido da Bruxa sumiu de forma misteriosa no desenrolar do enredo. $\mathrm{E}$ então, começaram a surgir alguns questionamentos das crianças: "Para onde foi o marido da Bruxa?"; "Será que ela pode nos visitar?".

No dia seguinte, com o objetivo de tornar o espaço da roda um lugar confortável, levamos um importante elemento: almofadas. Elas foram "presente especial" da Bruxa Onilda, que se comunicou com o Grupo por intermédio de cartas remetidas "magicamente". Nesta carta a Bruxa explicara que teria costurado as almofadas com as próprias mãos, trazendo ainda a sugestão: que as crianças pintassem suas almofadas. Desta forma, cada uma teria a sua para usar da maneira que quisesse, mas principalmente na roda.

A partir desta tarde, a Bruxa Onilda passou a se comunicar com as crianças por meio das cartas, que eram respondidas pelo Grupo nos momentos da roda, sempre levando curiosidades e questionamentos. Nós ficamos no "papel de escribas" e as crianças falavam o que gostariam de colocar na carta:

Na educação infantil, ler com os ouvidos e escrever com a boca (situação em que a professora ou o professor se põe na função enunciadora ou de escriba) é mais fundamental do que ler com os olhos e escrever com as próprias mãos. Ao ler com os ouvidos, a criança não apenas se experimenta na interlocução com o discurso escrito organizado, como vai compreendendo as modulações de voz que se anunciam num texto escrito. Ela aprende a sintaxe escrita, aprende as palavras escritas. (Britto, 2012, p.17)

O presente enviado pela Bruxa chegou à sala dentro de um grande saco preto, repleto de estrelas roxas e com um grande laço, 
também roxo - cor que a Bruxa Onilda adora. O movimento foi intenso, as crianças se aproximaram e logo tocaram e apalparam o saco para descobrir o que era. As almofadas, que eram feitas de tecido cru, precisavam ser pintadas - como sugestão da Bruxa. As crianças desejaram pintar as almofadas imediatamente com muito entusiasmo. No dia seguinte realizamos as pinturas e as almofadas se transformaram em verdadeiras obras de arte!

Durante as proposições, as contações de histórias da Bruxa Onilda e as atividades propostas, olhares atentos e reflexivos das crianças começaram a ser notados. Com isto, passamos a sensibilizar o nosso próprio olhar para estes momentos, a fim de perceber se nossas proposições estavam sendo verdadeiramente significativas. Estávamos desafiadas a pensar o momento da roda como um espaço de troca de diálogo entre diferentes sujeitos.

Refletimos sobre esta roda como um lugar das crianças, que fosse convidativo e prazeroso de estar, distinto de um momento rotineiro para meros encaminhamentos. Portanto, desejamos fazer deste espaço não somente de diálogo, mas repleto de sentidos e significados para todos. Tornando-o um lugar do imaginário, da fantasia, onde pudéssemos partilhar momentos de aventuras com o Grupo a partir de histórias intencionalmente escolhidas.

Continuamos com o objetivo de tornar o momento da roda um espaço aconchegante de contar e ouvir histórias e, para isto, levamos grandes tapetes artesanais. Estes "foram tecidos" pela própria Bruxa Onilda, enviados por ela como presente e, também fizeram parte da nossa roda. 
Junto aos tapetes, estava mais uma carta da Bruxa, onde carinhosamente explicava que o presente era para que as crianças usassem em muitos lugares (no pátio, em piqueniques, etc.). Ao tirar os tapetes da caixa de presente, as crianças pediram para olhar de perto. Movimento é o que definiu este momento: elas queriam tocar, puxar, rolar no tapete, sentir a textura e descobrir o presente tecido pelas mãos da própria Bruxa Onilda - como ela havia afirmado na carta. Resolvemos então, encontrar um lugar para colocar os tapetes, as crianças se mobilizaram e organizaram o tapete no lugar onde aconteceriam as rodas.

O nosso objetivo era humanizar o espaço da roda e, assim, despertar o desejo das crianças em participar deste momento de forma mais confortável e prazerosa. Com os novos elementos enviados pela Bruxa e com a participação das crianças em todo o processo, conseguimos tornar aquele espaço em um lugar, no sentido abaixo descrito:

As crianças vão interagindo com o espaço dando a ele significados diferentes, criando o novo, a partir do que está disponibilizado materialmente e imaterialmente, que são suas ideias, pensamentos, imaginações e fantasias, convidando-nos a resgatarmos nosso homo ludens, lançando sobre nós seu feitiço, fascinando-nos e cativando-nos, cheio de ritmo e harmonia. Nestes outros sentidos e significados que vão empregando no espaço e em tudo que nele está contido, as crianças vão indicando para o espaço da creche um lugar para brincar, onde o sonho e a fantasia são possíveis, aguçando em nós o desejo de que elas nos enfeiticem. (Agostinho, 2004, p. 09) 
Com os tapetes e as almofadas aquele "pedacinho" da sala de referência, que nos parecia tão pequenino, tornou-se grandioso: lá não aconteciam somente as rodas, lá as crianças brincavam, liam, descansavam, enfim, aquele pedacinho de sala se transformou em um lugar onde as crianças gostavam de ficar. Aquele espaço foi modificado e passou a ser um lugar especialmente convidativo, um lugar onde as crianças se sentiam verdadeiramente desejosas de estar.

Assim, demos continuidade às nossas proposições e naquele lugar aconteceram diferentes contações de histórias, leituras de livros, visitas inesperadas, leitura e escrita de cartas. Nem sempre estes momentos aconteceram com a roda na forma circular, pois, naquele lugar as crianças se punham como gostariam de estar: deitadas, por vezes de barriga pra cima ou de barriga pra baixo, abraçadas nas almofadas ou sentadas nelas.

Aquele lugar socialmente construído para e com as crianças foi o locus da nossa ação. Entendemos a roda, não como um círculo fixo, mas um movimento de estar com o outro de maneira respeitosa. E assim, foi possível proporcionar uma roda confortável para que acontecessem as próximas vivências do estágio.

\section{A roda e a Bruxa "Ozenilda"}

Ozenilda $^{5}$ era uma bruxa boa, prima da Bruxa Onilda, nascida em Florianópolis, portanto, uma "Bruxa manezinha da Ilha". Ela foi

\footnotetext{
${ }^{5}$ A Bruxa Ozenilda é uma personagem criada por nós para estabelecer um diálogo entre as histórias da Bruxa Onilda e o projeto desenvolvido pelas professoras do Grupo. Foi interpretada por Fernanda Gonçalves.
} 
visitar o Grupo para levar notícias da prima Onilda e realizar contação de história sobre lendas catarinenses.

Planejamos com cuidado como realizar essa visita, de modo a provocar os sentidos das crianças, propiciando uma experiência significativa para o Grupo. A reação das crianças foi incrível, algumas espantadas, outras curiosas:

Quando apareci na porta a expressão nos rostos das crianças de surpresa, espanto, susto, alegria e encantamento foi impressionante. Aproximei-me de algumas das crianças, elas me olhavam espantadas $e$ curiosas.

Sentei-me junto às crianças, em uma cadeira que tinha sido deixada especialmente para Bruxa, logo começaram as perguntas: "Você é a Bruxa Onilda?"; Você é Bruxa de verdade?"; "Da onde você veio?". E então eu me apresentei: "Olá crianças, aqui que é o GTV?”- Elas em coro respondem: "Simmmmmmm!".

Eu continuo minha apresentação: "Eu sou a prima da Bruxa Onilda, me chamo Ozenilda e sou manezinha da ilha, moro aqui em Florianópolis! Vocês estão aprendendo sobre Florianópolis?" - As crianças respondem que sim. Algumas crianças ficaram desconfiadas que eu era a "Fernanda" e não a Bruxa Ozenilda, e por mais que me esforçasse para mudar a voz, uma criança falou: "Sua voz tá parecida com a da Fernanda!" - Eu logo questiono: "Fernanda?" - Afinando ainda mais a voz - "Quem é essa Fernanda?" - E algumas crianças me respondem que Fernanda era uma estagiária que não tinha vindo aquele dia.

E escuto outro questionamento: "Mas porque tem uma corda no seu rosto?" (Uma criança pergunta a respeito do elástico que prendia 
meu nariz de bruxa, que fizemos de tudo para escondê-lo e disfarçá-lo, mas ele conseguiu perceber). Eu então respondo de forma improvisada: "Essa corda serve para segurar minha cara! Eu tenho 250 anos, sabia? E quando se chega aos 250 anos só segurando mesmo a cara, para ela não cair!" - E as crianças soltaram uma gargalhada deliciosa. (REGISTRO DE PROPOSIÇÃO, 08/05/2012).

As crianças do Grupo se permitiram participar da brincadeira, mesmo aquelas que desconfiaram que a Bruxa não era de verdade. As crianças entraram no mundo do faz-de-conta, brincaram e interagiram muito encantadas, com a prima da Bruxa Onilda:

Contei a lenda catarinense "Os cabelos de Dalva" e as crianças se envolveram muito. Pude captar olhares curiosos, desejosos da escuta daquela contação de história bruxólica. Percebi olhares atentos, expressões de medo, de envolvimento, enfim, a resposta do Grupo foi maravilhosa e de fato, nosso objetivo principal estava se cumprindo: propiciar uma experiência significativa para as crianças. (REGISTRO DE PROPOSIÇÃO, 08/05/2012)

Neste momento, novamente os olhares atentos despertaram nossa curiosidade, e percebemos o quanto aquela vivência tinha sido significativa para as crianças, estagiárias e professoras do grupo.

\section{A roda e o Pescador João}

No penúltimo dia de proposição do estágio, recebemos mais uma carta da Bruxa Onilda. Na carta ela apontava para mais uma visita especial e misteriosa. Eis que entra pela porta da sala, um senhor 
carregando uma rede de pesca artesanal, vestido de calças “arregaçadas”, camisa xadrez e um chapéu de palha. Ele se apresentou como Pescador João e disse que tinha ido até a Creche visitar o GTV para contar um pouco das suas histórias de pescador.

João era um pescador, nativo da Ilha de Florianópolis interpretado por Fernando Gonçalves, que de fato é nativo da vila de pescadores da Barra da Lagoa ${ }^{6}$.

O Grupo ficou entusiasmado e surpreso com a visita. As crianças queriam tocar a rede de pesca e olhar de perto aquele objeto. Ao perceber a curiosidade das crianças a respeito da sua rede, o Pescador iniciou sua contação de histórias e mostrou como é o movimento de "tarrafear". Ele ensinou como se joga uma rede no mar e, neste momento as crianças estavam especialmente envolvidas: o silêncio era total. Conseguimos captar os olhares atentos e curiosos de muitas crianças, olhares investigativos, olhares alegres, olhares felizes: olhares de encantamento.

O Pescador sensibilizado pela curiosidade dos pequenos investigativos e curiosos, solta um convite (com um sotaque caracteristicamente ilhéu): "Alguém quer ser pescado?" - uma das meninas pula rapidamente, dando um salto ao lado do pescador falando: "Eu quero!" - E ele responde: "Então você será minha sereia!". As crianças dão uma gargalhada em coro. Organizamos as crianças para se afastarem um pouco da rede, dando espaço para o Pescador realizar o movimento. A "nossa sereia” ficou em pé ao lado do Pescador, que vagarosamente realiza o movimento de tarrafear, com cuidado para não machucar a

\footnotetext{
${ }^{6}$ Praia do município de Florianópolis muito conhecida pela atividade pesqueira.
} 
menina, tentando se aproximar do movimento real da pesca. As crianças adoraram visualizar a "sereia" ser pescada por João, os olhos de encantamento não paravam de brilhar. (REGISTRO DE PROPOSIÇÃO, 09/05/2012)

Ao final de sua visita, o pescador deixou de presente para as crianças conchinhas de berbigão para que elas brincassem no parque. No fim, este presente virou arte! As crianças criaram verdadeiras obras de arte: mandalas, bonecas, estradas para brincar com carrinhos e o parque virou um ateliê a céu aberto.

Foi realmente maravilhoso o envolvimento do Grupo e não existe outra coisa que defina esta tarde senão "os olhares de encantamentos" das crianças, que encantaram os meus $e$ principalmente o meu coração. (REGISTRO DE PROPOSIÇÃO, 09/05/2012)

Estes dois momentos de contação de histórias foram especialmente significativos. As crianças se envolveram muito com as narrativas e com os personagens deixando fluir a imaginação. Concordamos com Gilka Giradello quando nos diz que:

Um laço indissolúvel une a narrativa à imaginação, e as crianças têm necessidade das imagens fornecidas pelas histórias como estímulo para sua própria criação subjetiva, para sua exploração estética e afetiva dos meandros do mundo. A necessidade de histórias tem sido identificada como um aspecto central na vida imaginativa das crianças. As histórias permitem um exercício constante da imaginação em seu aspecto mais visual. Isso ocorre tanto em relação aos contos literários quanto aos casos contados no meio das 
conversas, tão apreciados pelas crianças. (Girardello, 2011, p. 82)

A contação de história mostrou-se para nós, como um momento de encantamentos, do lúdico e do imaginativo, cuja realidade e fantasia dialogavam a todo instante.

\section{Olhares de encantamento: algumas considerações}

"Um fotógrafo-artista me disse outra vez: Veja que pingo de sol no couro de um lagarto é para nós mais importante do que o sol inteiro no corpo do mar. Falou mais: que a importância de uma coisa não se mede com fita métrica nem com balanças nem com barômetros etc. Que a importância de uma coisa há que ser medida pelo encantamento que a coisa produza em nós. Assim um passarinho nas mãos de uma criança é mais importante para ela do que a Cordilheira dos Andes. [...]" (Barros, 2010, p.109).

Iniciamos nossas considerações usando das palavras de Manoel de Barros, pois estas traduzem com perfeição o sentido que o Estágio Supervisionado em Educação Infantil tomou para nós.

A Viagem junto ao GTV se constituiu repleta de significados, desafios, questionamentos, "mundos bruxólicos", "cartas misteriosas", "visitas inesperadas": o faz-de-conta que dialogava a todo o momento com a realidade e a fantasia e que causou tanto encantamento nas crianças - e também em nós. É neste sentido que usamos das palavras do poeta quando nos diz que "a importância de uma coisa há que ser medida pelo encantamento que a coisa produza em nós" (Idem).

Propiciar experiências que as tocassem profundamente era um dos nossos grandes desejos. Viajar ao mundo do faz-de-conta, do 
inusitado e da fantasia, onde as crianças se permitissem embarcar nessa viagem e se sentissem livres para mudar a rota, nos mostrando novos caminhos, novos desafios, novas descobertas.

O momento da roda que inicialmente parecia "desinteressante" para as crianças, passou a acontecer de maneira mais aconchegante. No final das proposições as crianças já estavam se organizando de forma independente, chamando atenção umas das outras quanto à necessidade de fazer silêncio e respeitar a vez do outro falar. $\mathrm{O}$ mais gratificante foi perceber o quanto passaram a se sentir confortáveis e acolhidas naquele momento, se permitindo deitar para ouvir uma história, esticar seu corpo quase como uma tentativa de se "espreguiçar" - movimento que nos remete a conforto e bem estar. Concordamos com Agostinho, quando nos indica que,

O espaço da creche tem de propiciar um ninho seguro, um lugar que a criança possa considerar seu, possa estar consigo mesma, num encontro íntimo com seus ritmos, pulsações e sentimentos. Um lugar em que ela tenha segurança e confiança, oportunizando sentido de pertencimento e lhe seja assegurada sua identidade pessoal. Enfim, que tenha direito e estar só, momentos de quietude, num encontro com o que lhe é mais profundo e íntimo, resguardada sua individualidade. (Agostinho, 2004, p. 13)

Pensar o cotidiano da educação infantil significa um esforço para não se deixar conformar com o que já está posto, mas ponderar e refletir sobre os fazeres tácitos que são reproduzidos e que não garantem uma educação emancipadora. A infância é a condição social de ser criança e a garantia de vivê-la plenamente vai depender das experiências e das relações sociais que o adulto permitir que essa criança estabel eça. 
Neste sentido, acreditamos que o espaço da creche deve ser o lugar privilegiando da criança viver sua infância e, portanto, este lugar deve ser repleto de sentidos e significados para ela. Que faça parte da sua identidade e do seu processo de tornar-se humana.

Naquele lugar tão especialmente gostoso de estar, onde tantas histórias e visitas emocionantes aconteceram, era também o lugar da leitura. Durante as vivências do estágio, levamos diferentes títulos para que as crianças ficassem a vontade para ler, se assim desejassem (os preferidos eram sempre os livros da Bruxa Onilda). Os pequenos realizavam suas leituras do seu modo,

O contato do leitor com o objeto livro pela feição material, considerado aqui a primeira cerimônia de apropriação da leitura, leva-nos a refletir sobre as manifestações sensoriais advindas do relacionamento palpável entre o leitor e o livro. Poderíamos dizer que o leitor aproxima-se do livro estimulado pelos cinco sentidos. (Debus, 2006, p. 34)

Desta forma, a criança realiza suas primeiras leituras pelos sentidos, em contato com os elementos físicos do livro. A criança lê as imagens, a textura e até o cheiro, os "sentidos imperam nessa leitura que mexe com os prazeres do corpo numa relação que passa mais pela afetividade e sensibilidade a partir da consistência material do livro objeto" (Idem, p. 35). As crianças gostavam de estar com os livros e nosso objetivo era justamente construir bases para que elas participem criticamente da cultura escrita (Britto, 2012).

As crianças se desenvolvem e interagem com a realidade social, portanto, produzem cultura, elas procuram e desejam essa participação, 
pois, as relações sociais fazem parte de seu desenvolvimento e de suas vidas.

$$
\begin{aligned}
& \text { Interessante notar que as crianças estão a nos } \\
& \text { apontar as pistas que precisamos para construir } \\
& \text { um projeto de mundo verdadeiramente } \\
& \text { humanista, basta que abramos espaços para que } \\
& \text { elas possam anunciá-lo; fica o convite e o } \\
& \text { desafio deste encontro, baseado no } \\
& \text { relacionamento, comunicação e participação de } \\
& \text { todos os envolvidos com a creche num } \\
& \text { exercício de respeito comum. (Agostinho, 2004, } \\
& \text { p.12) }
\end{aligned}
$$

Concordando com Agostinho, para finalizar nossas reflexões usamos suas palavras para reafirmar um convite: é preciso dar voz e vez para que as crianças participem efetivamente da história, como uma real possibilidade da promoção desses atores sociais virarem protagonistas. 


\section{REFERÊNCIAS}

AGOSTINHO, Kátia Adair. O espaço da creche: que lugar é este? In $27^{\mathrm{a}}$ Reunião Anual ANPEd, Caxambu, 2004. Disponível em htttp://www.anped.org.br/reuniões/27/gt07/t073.pedf Último acesso em 7 de Dezembro. 2011.

BARROS, Manoel de. Memórias inventadas: As infâncias de Manoel de Barros. Editora Planeta do Brasil. São Paulo, 2010.

BATISTA, Rosa. CERISARA, Ana Beatriz; OLIVEIRA, Alessandra M. R. \& RIVERO, Andréa S. Partilhando olhares sobre as crianças pequenas: reflexões sobre o estágio na educação infantil. In $12^{\circ}$ Encontro Nacional de Prática de Ensino (ENDIPE), Curitiba, 2004.

BRITTO, Luiz Percival Leme. Letramento e alfabetização: implicações para a educação infantil. In: FARIA, Ana Lúcia Goulart de; MELLO, Suely Amaral. (Orgs.). O mundo da escrita no universo da pequena infância. Campinas: Autores Associados, 2012. 3. ed. p. 03-19.

DE ANGELO, Adilson. O espaço-tempo da fala na educação infantil: a roda de conversa como dispositivo pedagógico. In. ROCHA, Eloisa A. Candal; KRAMER, Sônia (orgs.). Educação Infantil: enfoques em diálogo. Campinas, SP: Papirus, 2011.

DEBUS, Eliane Santana Dias. Festaria de brincança: a leitura literária na educação infantil. São Paulo: Paulus, 2006

GANDINI, Lella. Espaços Educacionais e de Envolvimento Pessoal. In EDWARDS, C., FORMAN, G. e GANDINI, L. As Cem Linguagens da Criança: A Abordagem de Reggio Emilia na Educação Infantil. Porto alegre: Artes Médicas, 1999. 
GIRARDELLO, Gilka. Imaginação: arte e ciência na infância . ProPosições, Ago 2011, vol.22, no.2, p.72-92. ISSN 0103-7307.

LAITANO, Paloma Esteves. A Bruxa Onilda e sua trajetória heróica: uma representação da bruxa como herói na literatura infantil. Letrônica, v. 1 , n. 1 , p. 243 - 255, dezembro de 2008. Disponível em http://revistaseletronicas.pucrs.br/ojs/index.php/letronica/article/viewFil e/4279/3560 Ultimo acesso: 19 de julho de 2012.

ROCHA, Eloísa A. Candal. e OSTETTO, Luciana E. O estágio na formação universitária de professores de educação infantil. In: SEARA, Izabel C., DIAS, Maria de Fátima S., OSTETTO, Luciana E. e CASSIANI, Suzani.(Orgs.) Práticas pedagógicas e estágios: diálogos com a cultura escolar. Florianópolis: Letras Contemporâneas, 2008, p.103-116. 